\title{
ESTIMATING THE ORAL BIOAVAILABILITY OF METHYLMERCURY TO CHANNEL CATFISH (ICTALURUS PUNCTATUS)
}

\author{
John T. McCloskey, *† Irvin R. Schultz, $\$$ and Michael C. Newman $\$$ \\ $\dagger$ University of Georgia, Savannah River Ecology Laboratory, P.O. Drawer E, Aiken, South Carolina 29802, USA \\ $\ddagger$ Battelle PNNL, Molecular Biosciences, P.O. Box 999-P7-56, Richland, Washington 99352, USA \\ $\S$ College of William and Mary, Virginia Institute of Marine Science, P.O. Box 1346, Gloucester Point, Virginia 23062, USA
}

(Received 13 June 1997; Accepted 29 October 1997)

\begin{abstract}
In classical pharmacology, oral bioavailability of a toxicant is defined as that fraction of an orally administered dose reaching the systemic circulation of the animal. The present study estimates the bioavailability of methylmercury in channel catfish (Ictalurus punctatus) by comparing concentrations in the blood through time after oral and intra-arterial (IA) administration. Catfish were cannulated in the dorsal aorta and gavaged a pelleted feed that had been spiked with methylmercury. Each catfish was gavaged an increasing amount of spiked feed. Following oral dosing, serial blood samples were removed for more than 1,500 h. One month after removal of the last blood sample, the same fish were injected IA with methylmercury and serial blood samples were removed for more than $3,000 \mathrm{~h}$. The area under the curve of the blood concentration-time curve extrapolated to infinity $\left(\mathrm{AUC}_{0 \rightarrow \infty}\right) \mathrm{was}$ calculated from fish dosed orally and IA using both noncompartmental (trapezoidal) and compartmental methods. Bioavailability was estimated as the ratio of the dose-corrected oral $\mathrm{AUC}_{0 \rightarrow \infty}$ to the IA $\mathrm{AUC}_{0 \rightarrow \infty}$. Average bioavailability estimates from this approach were 33\% using noncompartmental (range 14-55\%) and 29\% using compartmental (range 12-42\%) methods and were correlated with the amount of food gavaged to the fish $\left(r^{2}=0.95, p=0.026\right)$. Bioavailability estimates using the present methods were much lower than estimates using more conventional methods (i.e., assimilation efficiency estimates using mass balance), suggesting that conventional methods may overestimate the true bioavailability of toxicants in fish.
\end{abstract}

Keywords-Oral bioavailability Methylmercury Channel catfish Elimination Uptake

\section{INTRODUCTION}

High levels of mercury in aquatic organisms are a continuing concern in ecotoxicology. The primary chemical form of mercury found in aquatic organisms is methylmercury $\left(\mathrm{CH}_{3} \mathrm{Hg}\right)$ [1]. The bioaccumulation of $\mathrm{CH}_{3} \mathrm{Hg}$ from food is a more important route of uptake in fish than from the water [2]. Consequently, accurate estimates of $\mathrm{CH}_{3} \mathrm{Hg}$ bioaccumulation from food are important to generate realistic models of bioaccumulation. These bioacumulation models can then be used to estimate the concentration of $\mathrm{CH}_{3} \mathrm{Hg}$ reaching target organs.

In ecotoxicology, bioavailability can be broadly defined as the portion of a chemical in the environment that is available for biological action, such as uptake by an organism [3]. Oral bioavailability, which is the portion of a chemical in food that is available for uptake by an organism, is one type of bioavailability of particular interest. It is closely linked to the pharmacological definition of bioavailability, which specifically refers to the fraction of an orally administered dose (e.g., in food) that reaches the systemic circulation of the animal [4]. In pharmacology, bioavailability is most often calculated from the ratio of the areas under the blood concentration-time curves (AUCs) of orally and intravascularly administered doses of a drug or toxicant [4]. Such measures of bioavailability are routinely measured for drugs in pharmacology [4] and for compounds pertinent to aquaculture with fish [5-7], mainly because of their fairly rapid elimination or metabolism. This

* To whom correspondence may be addressed (john_mccloskey@fws.gov). The current address of J.T. McCloskey is U.S. Fish and Wildlife Service, P. O. Box 99, Gloucester, VA 23061. method for measuring bioavailability remains an underutilized method in ecotoxicology [8].

In ecotoxicology, the conventional approach involves feeding groups of individuals known amounts of toxicant over a period of time. The portion of the total dose retained in the organism at the end of the feeding period is measured after withholding of food for sufficient time to allow complete clearance of the food from the gut. Bioavailability is then estimated by mass balance under the assumption that all toxicant measured in the organism is assimilated. In ecotoxicology, this more conventional method does provide an adequate estimate of oral bioavailability, providing the compound has a relatively slow elimination phase. Using this conventional approach, bioavailability of $\mathrm{CH}_{3} \mathrm{Hg}$ from oral solutions or commercial foods is high and has been reported to be between 70 to $90 \%$ in goldfish (Carassius auratus) [9] and between 50 to $70 \%$ in rainbow trout (Oncorhynchus mykiss) [2,10,11]. The bioavailability of $\mathrm{CH}_{3} \mathrm{Hg}$ from natural prey items was generally much lower $(<50 \%)[12,13]$, presumably because of the lower digestibility of natural prey items relative to commercial foods.

The purpose of the present study was to use the pharmacological method to estimate the bioavailability of $\mathrm{CH}_{3} \mathrm{Hg}$ from food in channel catfish (Ictalurus punctatus). The methods used in the present study will be distinct as the AUCs after oral and intravascular administration were measured sequentially in the same fish. In contrast, other studies estimating bioavailability using this approach measured oral and intravascular AUCs in different groups of fish [5-7,14], increasing the variation in the resulting estimates. This pharmacological approach has been used rarely in ecotoxicology and has never been used for $\mathrm{CH}_{3} \mathrm{Hg}$ in fish. 


\section{MATERIALS AND METHODS}

\section{Fish maintenance}

Adult channel catfish of mixed sex were obtained from local suppliers. Immediately upon arrival at the laboratory, all fish received a $2-\mathrm{h}$ treatment in a $0.25-\mathrm{mg} / \mathrm{L}$ solution of malachite green (Sigma Chemical, St. Louis, MO, USA). Catfish were initially held outdoors in 2,800-L, polyethylene-lined, circular tanks for a minimum of 2 weeks before transfer to indoor aquaria. Catfish were then maintained in a 1,000-L polyethylene tank (Rubbermaid, Winchester, VA, USA) containing reconstituted hard water [15] and $1 \%$ (w/v) $\mathrm{NaCl}$. All fish were held at $21^{\circ} \mathrm{C}$ for at least 1 week before use in experiments. Catfish were fed a maintenance ration of approximately $2 \%$ of their body mass three times per week with soft moist pelleted feed (Rangen, Buhl, ID, USA).

\section{Water quality}

Measurements of water quality in the holding tank were made weekly. Temperature, dissolved oxygen, and conductivity were measured using a Hydrolab (model SVR2-SU) Environmental Data System (Hydrolab, Austin, TX, USA). The $\mathrm{pH}$ was measured using a Radiometer Auto-Titrating System (Radiometer America, Westlake, OH, USA). Sodium concentrations were measured with a Perkin-Elmer (model 5100PC) atomic absorption spectrophotometer (Perkin-Elmer, Norwalk, CT, USA). Water quality parameters in the holding tank had the following characteristics (mean $\pm \mathrm{SD}, n=26$ ): temperature: $21.2 \pm 0.7^{\circ} \mathrm{C}$; dissolved oxygen: $8.5 \pm 0.2 \mathrm{mg} / \mathrm{L}$; conductivity: $2.81 \pm 0.09 \mathrm{mmhos} / \mathrm{cm} ; \mathrm{pH} 7.8$ (median, range $=$ 7.4-8.1); sodium: $0.49 \pm 0.02 \mathrm{~g} / \mathrm{L}$. Ammonia levels were monitored regularly to ensure that the concentration remained below $0.5 \mathrm{mg} / \mathrm{L}$. Fecal material was siphoned from cages and half of the water in the holding tank was replaced biweekly.

\section{Surgical procedures and blood removal}

Six catfish weighing $840 \pm 170 \mathrm{~g}$ (mean $\pm \mathrm{SD}$ ) were fitted with a dorsal aortic cannula using methods described previously $[16,17]$. Briefly, fish were anesthetized with $150 \mathrm{mg} / \mathrm{L}$ of MS-222. The cannula material was $28-G$ Teflon ${ }^{\text {(WW }}$ tubing (Zeus, Raritan, NJ, USA). An 18-G intravenous catheter (Angiocath ${ }^{\circledR}$, Becton Dickinson, Sandy, UT, USA) was used to guide the cannula into the dorsal aorta. The cannulated fish were held in 100-L polyethylene cages that were perforated to allow water exchange with the holding tank. The cages were placed into a round, recirculating water, 1,000-L polyethylene tank filled with reconstituted hard water and $1 \%$ o (w/v) $\mathrm{NaCl}$. The end of the cannula was attached to a 1-ml syringe that floated above the fish inside the cage. All fish were allowed to recover from surgery for at least $24 \mathrm{~h}$ before dosing.

\section{Dose preparation and administration}

The oral dose was prepared by spiking pelleted feed (Rangen) with $\mathrm{CH}_{3} \mathrm{HgCl}_{2}$ (>99\% pure, ICN Biomedical, Costa Mesa, CA, USA). Briefly, $76.95 \mathrm{~g}$ of dry food was blended to a powder using a commercial blender. The dry powdered food was spiked with $1.8 \mathrm{ml}$ of a $2.38-\mathrm{mg} / \mathrm{ml} \mathrm{CH} \mathrm{CH}_{3} \mathrm{Hg}$ (dissolved in ethanol) solution for a total of $4.30 \mathrm{mg}$. The food was blended again until thoroughly mixed. The spiked food was then mixed with $30.03 \mathrm{~g}$ of deionized water, placed in a covered Teflon beaker, and refrigerated for storage until dosing.

Oral dosing of cannulated catfish was performed using a modified $60-\mathrm{ml}$ syringe fitted with $15 \mathrm{~cm}$ of size 15 silicone tubing. The dosing syringe had the end hole enlarged so that food could be expelled more easily. Fish were placed in 150 $\mathrm{mg} / \mathrm{L}$ MS-222 until stage II anesthesia was induced. Symptoms of stage II anesthesia included loss of reactivity to external stimuli and decreased opercular movement and normal equilibrium [18]. The end of the silicone tubing was then gently inserted into the stomach of the anesthetized catfish and spiked food was slowly delivered directly into the stomach over a period of about $30 \mathrm{~s}$. The catfish was then placed back into a perforated cage to recover. The fish was checked periodically to make sure that none of the dose had been regurgitated. The dosing syringe was weighed before and after dosing of each fish to determine the weight $(\mathrm{g})$ of food injected. The administered dose of $\mathrm{CH}_{3} \mathrm{Hg}$ was $0.53 \pm 0.33 \mathrm{mg} \mathrm{CH} \mathrm{CH}_{3} \mathrm{Hg} / \mathrm{kg}$ fish (mean $\pm \mathrm{SD}, n=6$ ). Immediately after dosing, $0.5 \mathrm{~g}$ of the spiked food was transferred into a $15-\mathrm{ml}$ glass test tube containing $5 \mathrm{ml}$ of a $1 \%(\mathrm{w} / \mathrm{v}) \mathrm{NaCl}$ in $2 \mathrm{~N} \mathrm{HCl}$ and frozen for later determination of the $\mathrm{CH}_{3} \mathrm{Hg}$ concentration. After oral dosing of $\mathrm{CH}_{3} \mathrm{Hg}$, serial blood samples were taken through the cannula at $1,3,5,8,12,24,30,45,55,75,100,150$, and 200 h. After $200 \mathrm{~h}$, the cannula was removed while the fish was under anesthesia and the sample interval for blood removal was increased to approximately $250 \mathrm{~h}$. Sampling continued for over 1,500 h (62 d). After $200 \mathrm{~h}$, feeding was resumed at a rate of approximately $2 \%$ of their body mass $3 \mathrm{~d}$ per week. This ration level was sufficient to maintain the catfish within $90 \%$ of their initial body weight. Blood samples were not removed on days that fish were fed. The cumulative volume of blood removed via the cannula was less than $10 \%$ of the estimated blood volume of the fish (assumed to be $4 \%$ of body weight). After resumption of feeding, the removal of blood was limited to a maximum of $2 \%$ of the estimated blood volume $(0.40-0.75 \mathrm{ml})$ per 250 -h sample interval.

After a month recovery period following removal of the last blood sample (130 d after initial oral dosing), the same six catfish were again fitted with a dorsal aortic cannula as described previously. After a 24-h recovery, catfish received a $0.44-\mathrm{mg} / \mathrm{kg}$ intra-arterial (IA), bolus injection of $\mathrm{CH}_{3} \mathrm{HgCl}_{2}$ ( $>99 \%$ pure, ICN Biomedical) dissolved in $0.9 \%$ (w/v) $\mathrm{NaCl}$ and $5 \mathrm{mM} \mathrm{NaCO}_{3}$. This dose was chosen based on a previous study [17]. After $\mathrm{CH}_{3} \mathrm{Hg}$ injection, serial blood samples were taken through the cannula at $0.17,0.33,0.67,1,1.5,2,4,6$, $9,12,24,36,50,75,100,150,200$, and $300 \mathrm{~h}$. The cannula was removed after the $300-\mathrm{h}$ sample and later samples were obtained as described previously for the oral dosing.

\section{Analytical procedures}

Whole blood was assayed for $\mathrm{CH}_{3} \mathrm{Hg}$ using a Perkin-Elmer (model 5100ZL) graphite furnace atomic absorption spectrophotometer (GFAAS) [19], and a modification of methods described previously [17]. Briefly, aliquots of fresh blood (maximum volumes of $0.75 \mathrm{ml}$ ) were mixed with an equal volume of a $1 \% \mathrm{NaCl}(\mathrm{w} / \mathrm{v})$ and $2 \mathrm{~N} \mathrm{HCl}$ solution and immediately frozen at $-4^{\circ} \mathrm{C}$. Later, samples were thawed and the $\mathrm{CH}_{3} \mathrm{Hg}$ removed by quadruplicate extractions with $0.3 \mathrm{ml}$ of benzene. The benzene extracts were pooled and extracted with $0.5 \mathrm{ml}$ of a $2.5 \mathrm{mM} \mathrm{Na}_{2} \mathrm{~S}_{2} \mathrm{O}_{4}(>99.999 \%$ pure, Aldrich Chemical, Milwaukee, WI, USA) solution. The $\mathrm{Na}_{2} \mathrm{~S}_{2} \mathrm{O}_{4}$ layer was removed and the $\mathrm{CH}_{3} \mathrm{Hg}$ concentration determined directly by GFAAS. A standard curve of $\mathrm{CH}_{3} \mathrm{Hg}$ in $2.5 \mathrm{mM} \mathrm{Na}_{2} \mathrm{~S}_{2} \mathrm{O}_{4}$ was prepared each day of analysis. A set of three blood standards, spiked with a known amount of $\mathrm{CH}_{3} \mathrm{Hg}$ to encompass the expected concentration range of unknown samples were as- 
sayed simultaneously with experimental samples. The recovery of $\mathrm{CH}_{3} \mathrm{Hg}$ from spiked blood was $94 \pm 7 \%$ (mean $\pm \mathrm{SD}$, $n=30$ ). Because of the consistently high recovery of $\mathrm{CH}_{3} \mathrm{Hg}$ from spiked standards, the calculated $\mathrm{CH}_{3} \mathrm{Hg}$ concentrations were not corrected for recovery. The $\mathrm{CH}_{3} \mathrm{Hg}$ concentration in spiked food was assayed as described previously except that $\mathrm{CH}_{3} \mathrm{Hg}$ was removed with quadruplicate extractions of $2 \mathrm{ml}$ of benzene. The pooled benzene extracts ( $8 \mathrm{ml}$ total volume) were then back-extracted with $2 \mathrm{ml}$ of $\mathrm{Na}_{2} \mathrm{~S}_{2} \mathrm{O}_{4}$. The $\mathrm{Na}_{2} \mathrm{~S}_{2} \mathrm{O}_{4}$ layer was diluted 1:100 before GFAAS analysis. The recoveries of $\mathrm{CH}_{3} \mathrm{Hg}$ from food were similar as those obtained from blood.

The hematocrit of blood samples removed via the cannula was typically less than that of blood samples removed from anesthetized fish. This observation is consistent with previous reports indicating that the blood sampling protocol influences the hematocrit of fish [20]. Because the majority of $\mathrm{CH}_{3} \mathrm{Hg}$ in blood is associated with the RBC fraction [17], the blood concentrations of $\mathrm{CH}_{3} \mathrm{Hg}$ were corrected to an hct of $17 \%$, the mean hematocrit of fish before dosing. Blood hcts were similar following both oral and IA administration.

\section{Toxicokinetic analysis}

Two approaches for toxicokinetic data analysis were used: compartmental and noncompartmental. Both methods provide estimates of important kinetic parameters such as the steadystate volume of distribution and total body clearance but differ in their assumptions regarding the distribution of chemicals within the body [21]. In compartmental analysis, the body is assumed to be comprised of one or more homogeneous compartments. If the xenobiotic elimination exhibits a multiexponential pattern, the body is assumed to be composed of a central compartment and one or more peripheral compartments. Noncompartmental analysis assumes the xenobiotic is absorbed or administered into and excreted from a central pool without requiring a specific number or arrangement of peripheral pools $[21,22]$.

In practice, the two approaches differ primarily in the methods used to estimate the area under the blood concentrationtime profile $\left(\mathrm{AUC}_{0 \rightarrow \infty}\right)$. For the compartmental analysis performed in the present study, the observed data were fit to a triexponential equation to obtain estimates of the slopes of each portion of the curve $(\pi, \alpha, \beta)$ and the corresponding $Y$ intercepts $(A, B, C)$. Once estimates of these values were obtained, the $\mathrm{AUC}_{0 \rightarrow \infty}$ and other kinetic parameters can be calculated using the equations below. For noncompartmental analysis, the $\mathrm{AUC}_{0 \rightarrow \infty}$ was estimated using the linear trapezoidal method [23,24].

Both compartmental and noncompartmental analyses are commonly used methods for analyzing clinical pharmacokinetic data. Noncompartmental analysis is rarely applied in ecotoxicology, although this approach offers the advantages of less complicated calculations and fewer number of assumptions regarding the distribution of a chemical within the body. Compartmental analysis can provide more detailed information about the absorption and elimination processes but requires complicated curve-fitting procedures. Because both of these methods may be advantageous to ecotoxicological studies, both were used to determine if substantial differences in parameter estimates were produced.

Compartmental modeling was performed using an iterative, nonlinear least-squares computer program, PCNONLIN (Statistical Consultants). This program fit the blood concentration- time $\left(C_{b}, t\right)$ curves of $\mathrm{CH}_{3} \mathrm{Hg}$ after IA and oral dosing. Preliminary analysis indicated that the $C_{b}, t$ curve after oral dosing was best fit to a two-compartment pharmacokinetic model but the $C_{b}, t$ curve after IA dosing was best fit to a three-compartment pharmacokinetic model. This difference in the number of peripheral compartments between dosing routes has been reported for other xenobiotics in fish (e.g., [14,16]). The difference can be attributed to the initial, rapid exchange of $\mathrm{CH}_{3} \mathrm{Hg}$ between blood and well-perfused tissues seen after intravascular injection [17], which is obscured after oral dosing because the absorption process is slow relative to the exchange between compartments.

The following triexponential equation was used to fit the observed blood concentration-time profiles after IA dosing:

$$
C_{b}, t=A e^{-\pi t}+B e^{-\alpha t}+C e^{-\beta t}
$$

The area under the curve $\left(\mathrm{AUC}_{0 \rightarrow \infty}\right)$, was estimated as $\mathrm{AUC}_{0 \rightarrow \infty}=A / \pi+B / \alpha+C / \beta$. The biological half-life $\left(\mathrm{t}_{1 / 2}, \beta\right)$, mean residence time (MRT), area under the moment curve (AUMC), total body clearance $\left(\mathrm{Cl}_{b}\right)$, and apparent volume of distribution at steady state $\left(V_{\mathrm{ss}}\right)$, were estimated by the following equations: $t_{1 / 2, \beta}=0.693 / \beta$, MRT $=$ AUMC/AUC ${ }_{0 \rightarrow \infty}$ where $\mathrm{AUMC}=A / \pi^{2}+B / \alpha^{2}+C / \beta^{2}, C l_{b}=\operatorname{dose} / \mathrm{AUC}_{0 \rightarrow \infty}$ and $V_{\mathrm{ss}}=C l_{b}$ MRT. The maximum blood concentration $\left(C_{\max }\right)$ following IA dosing was calculated as: $C_{\max }=A+B+C$, while $C_{\max }$ and the time to maximum blood concentration $\left(T_{\max }\right)$ following oral dosing were calculated as described previously [24].

There was a noticeable delay in the appearance of $\mathrm{CH}_{3} \mathrm{Hg}$ in blood after oral dosing and the following equation, which describes the first-order uptake (with a lag time) and the biexponential decline of $\mathrm{CH}_{3} \mathrm{Hg}$ from blood, was used to fit the observed concentration-time profiles:

$$
\begin{aligned}
C_{b}, t=K_{a} D\left(\frac{F}{V_{1}}\right)[ & \frac{\left(k_{21}-\alpha\right) e^{-a(t-\mathrm{lag})}}{\left(K_{a}-\alpha\right)(\beta-\alpha)}+\frac{\left(k_{21}-\beta\right) e^{-\beta(t-\mathrm{lag})}}{\left(K_{a}-\beta\right)(\alpha-\beta)} \\
& \left.+\frac{\left(k_{21}-K_{a}\right) e^{-K_{a}(t-\mathrm{lag})}}{\left(\alpha-K_{a}\right)\left(\beta-K_{a}\right)}\right]
\end{aligned}
$$

where $K_{\mathrm{a}}=$ first order absorption rate constant, $\left(F / V_{l}\right)=$ ratio of bioavailability and the volume of the central compartment, $D=$ dose, $k_{21}=$ first-order rate constant describing the transfer between the peripheral and central compartment, and lag = the lag time or delay in absorption of $\mathrm{CH}_{3} \mathrm{Hg}$ from the gut.

Noncompartmental analysis of the oral and IA blood curves was performed by calculating the $\mathrm{AUC}_{0 \rightarrow \infty}$ and $\mathrm{AUMC}$ using the linear trapezoidal method with the area from the last sampling time to infinity calculated from the slope of the terminal portion of the concentration-time profile $(\beta)[23,25]$. The $C l_{b}$, $V_{\mathrm{ss}}, t_{1 / 2, \beta}$ and MRT were then calculated using equations described previously [23]. $C_{\max }$ and $T_{\max }$ were the observed values from the raw data. The oral bioavailability $(F)$ was calculated from the following equation:

$$
F=\left(\text { AUC }_{0 \rightarrow \infty} \text { oral/AUC }{ }_{0 \rightarrow \infty} \text { IA }\right) \cdot(\text { dose IA/dose oral })
$$

\section{RESULTS}

All six fish that received an oral dose of $\mathrm{CH}_{3} \mathrm{Hg}$ survived the initial 1,500 $\mathrm{h}$ of blood sampling. After the 28-d recovery from blood sampling, these fish were fitted again with a dorsal aortic cannula and given an IA bolus injection of $\mathrm{CH}_{3} \mathrm{Hg}$. Of the six fish injected IA, four survived blood sampling to 1,000 to $1,500 \mathrm{~h}$. One fish died after pulling the cannula out $2 \mathrm{~h}$ 
Table 1. Toxicokinetic parameter estimates (mean $\pm \mathrm{SD}$ ) from blood concentration-time curves ${ }^{\mathrm{a}}$

\begin{tabular}{|c|c|c|c|c|}
\hline \multirow[b]{2}{*}{ Parameter } & \multicolumn{2}{|c|}{ Noncompartmental modeling } & \multicolumn{2}{|c|}{ Compartmental modeling } \\
\hline & Intra-arterial $^{\mathrm{b}}$ & Oral $^{c}$ & Intra-arterial $^{\mathrm{b}}$ & Oral $^{c}$ \\
\hline $\operatorname{AUC}_{0 \rightarrow \infty}(\mathrm{ng} / \mathrm{ml} \mathrm{h})$ & $129,240 \pm 41,816$ & $31,069 \pm 18,369$ & $151,054 \pm 64,414$ & $29,299 \pm 14,226$ \\
\hline$C_{\max }(\mathrm{ng} / \mathrm{ml})$ & $5,498 \pm 715^{\mathrm{d}}$ & $111 \pm 47^{\mathrm{d}}$ & $4,436 \pm 1,193$ & $86 \pm 43$ \\
\hline$T_{\max }(\mathrm{h})$ & $\mathrm{NA}^{\mathrm{e}}$ & $27 \pm 14^{\mathrm{d}}$ & NA & $38 \pm 20$ \\
\hline$V_{\mathrm{ss}}(\mathrm{ml} / \mathrm{g})$ & $4.0 \pm 2.2$ & NA & $5.9 \pm 3.2$ & NA \\
\hline$C l_{b}(\mathrm{ml} / \mathrm{h} \mathrm{g})$ & $0.0042 \pm 0.0016$ & NA & $0.0039 \pm 0.0018$ & NA \\
\hline$t_{1 / 2}(\mathrm{~h})$ & $477 \pm 163$ & $563 \pm 347$ & $1,473 \pm 758$ & $818 \pm 202$ \\
\hline MRT (h) & $916 \pm 366$ & $652 \pm 226$ & $1,641 \pm 912$ & NA \\
\hline$K_{\mathrm{a}}(\mathrm{ng} / \mathrm{h})$ & NA & NA & NA & $0.136 \pm 0.160$ \\
\hline Lag (h) & NA & NA & NA & $3.4 \pm 1.7$ \\
\hline
\end{tabular}

${ }^{a}$ Area under the blood concentration-time curve extrapolated to infinity $\left(\mathrm{AUC}_{0 \rightarrow \infty}\right)$ and maximum blood concentration $\left(C_{\max }\right)$ are normalized to a $\mathrm{CH}_{3} \mathrm{Hg}$ dose of $0.5 \mathrm{mg} / \mathrm{kg}$. Parameter estimates were calculated by PCNONLIN program.

${ }^{\mathrm{b}} n=4$.

${ }^{\mathrm{c}} n=6$.

${ }^{\mathrm{d}}$ Observed values from raw data.

${ }^{\mathrm{e}} \mathrm{NA}=$ not applicable.

postinjection and the other fish died at approximately $100 \mathrm{~h}$ postinjection. These two fish were not included in bioavailability estimations.

After oral dosing, there was a short lag-time (lag) that lasted approximately $4 \mathrm{~h}$ before the appearance of $\mathrm{CH}_{3} \mathrm{Hg}$ in the blood (Table 1). Once $\mathrm{CH}_{3} \mathrm{Hg}$ appeared in the blood, the concentration steadily increased and reached a maximum concentration $\left(\mathrm{C}_{\max }\right)$ of approximately $100 \mathrm{ng} / \mathrm{ml}$ at about $30 \mathrm{~h}\left(\mathrm{~T}_{\max }\right.$, Table 1 and Fig. 1). This was followed by a biexponential decline in the blood concentrations of $\mathrm{CH}_{3} \mathrm{Hg}$, which was qualitatively similar to that observed after IA dosing (Fig. 1, inset). The biological half-life of the terminal elimination phase $\left(t_{1 / 2}\right)$ was approximately $700 \mathrm{~h}$, and the mean residence time (MRT) was approximately $650 \mathrm{~h}$ (Table 1 ).

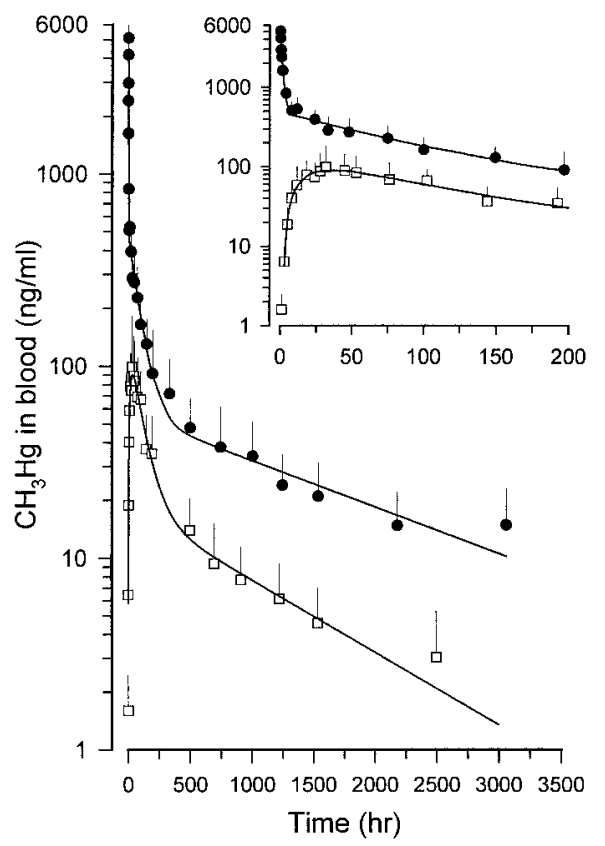

Fig. 1. Methylmercury concentrations in blood of channel catfish following intra-arterial ( ) and oral ( $\square$ ) administration. Blood concentrations are corrected to a dose of $0.5 \mathrm{mg}$ methylmercury $/ \mathrm{kg}$ fish. Symbols represent experimentally determined values (mean $\pm \mathrm{SD}, n$ $=4-6$ ) and the line is the least-squares fit to either Equation 1 (intraarterial) or Equation 2 (oral). Error bars not shown fit within the data point.
After IA dosing, concentrations of $\mathrm{CH}_{3} \mathrm{Hg}$ in blood were initially very high with a maximum blood concentration $\left(\mathrm{C}_{\max }\right)$ of approximately 5,000 ng/ml (Table 1 and Fig. 1). Blood concentrations declined in a triexponential manner with an initially rapid decline lasting 12 to $24 \mathrm{~h}$ followed by a decline similar to $\mathrm{CH}_{3} \mathrm{Hg}$ concentrations observed after oral dosing (Fig. 1). The log-linear portion of the blood curves after both dosing routes appeared to occur after $250 \mathrm{~h}$ (Fig. 1). The biological half-life of the terminal elimination phase $\left(t_{1 / 2}\right)$ was approximately $1,000 \mathrm{~h}$, and the MRT was approximately 1,300 $\mathrm{h}$ (Table 1). The apparent volume of distribution at steady state $\left(V_{\mathrm{ss}}\right)$, which relates the amount of $\mathrm{CH}_{3} \mathrm{Hg}$ in the fish to the concentration in the reference fluid (blood), was approximately $5 \mathrm{ml} / \mathrm{g}$ (Table 1$)$. The total body clearance $\left(\mathrm{Cl}_{b}\right)$, which represents the volume of blood that is completely cleared of $\mathrm{CH}_{3} \mathrm{Hg}$ per hour, was approximately $0.004 \mathrm{ml} / \mathrm{h}$ g (Table 1 ).

Comparison of the estimates obtained from both methods of toxicokinetic analysis revealed few differences (Table 1). The major differences in parameter estimates between methods were with $t_{1 / 2}$ and MRT, which differed by several hundred hours (Table 1). Similar AUCs resulted in comparable oral bioavailability estimates, regardless of the method (Table 2). Bioavailability estimates averaged 33\% (range 14-55\%) when using AUCs obtained from noncompartmental analysis and $29 \%$ (range 12-42\%) when using AUCs obtained from compartmental analysis (Table 2). In general, bioavailability estimates were higher using AUC estimates from noncompartmental analyses than when using AUC estimates from compartmental analyses (Table 2). There was a statistically significant $(\alpha=0.05)$ positive relationship between the amount of food gavaged to the fish and oral bioavailability (Fig. 2, $r^{2}$ $=0.95, p=0.026$ ). There was a negative relationship between the amount of food gavaged to the fish and oral AUC (Fig. 2 ), although this relationship was not statistically significant $\left(r^{2}=0.54, p=0.096\right)$.

\section{DISCUSSION}

The mean estimates of $\mathrm{CH}_{3} \mathrm{Hg}$ bioavailability using the present methodology (29 and 33\%) were lower than previously reported estimates of bioavailability using more conventional approaches [2,9-11]. Previously reported estimates of oral bioavailability for solutions [10] and commercial foods in fish range from 50 to $90 \%[2,9,11]$. The most significant difference 
Table 2. Bioavailability $(F)$ estimates from the ratio of the area under the blood concentration-time curve extrapolated to infinity $\left(\mathrm{AUC}_{0 \rightarrow \infty}\right)$ for the oral and intra-arterially (IA) dosed fish ${ }^{\mathrm{a}}$

\begin{tabular}{|c|c|c|c|c|c|}
\hline Catfish & Sex & $\begin{array}{l}\text { Type of } \\
\text { modeling }\end{array}$ & IA $\mathrm{AUC}_{0 \rightarrow \infty}$ & Oral $\mathrm{AUC}_{0 \rightarrow \infty}$ & Bioavailability $(F)$ \\
\hline \multirow[t]{2}{*}{1} & q & $\mathrm{NC}$ & 111,608 & 61,801 & 0.55 \\
\hline & & $\mathrm{C}$ & 116,358 & 48,709 & 0.42 \\
\hline \multirow[t]{2}{*}{4} & 0 & $\mathrm{NC}$ & 78,671 & 29,437 & 0.37 \\
\hline & & $\mathrm{C}$ & 79,621 & 29,470 & 0.37 \\
\hline \multirow[t]{2}{*}{5} & q & $\mathrm{NC}$ & 158,243 & 42,394 & 0.27 \\
\hline & & $\mathrm{C}$ & 187,892 & 42,779 & 0.23 \\
\hline \multirow[t]{2}{*}{6} & 0 & $\mathrm{NC}$ & 168,437 & 24,277 & 0.14 \\
\hline & & $\mathrm{C}$ & 220,086 & 26,137 & 0.12 \\
\hline \multirow[t]{2}{*}{ Mean \pm SD } & & $\mathrm{NC}$ & & & $0.33 \pm 0.17$ \\
\hline & & $\mathrm{C}$ & & & $0.29 \pm 0.14$ \\
\hline
\end{tabular}

${ }^{a}$ The AUCs were estimated using either noncompartmental (NC) or compartmental (C) methods and are corrected to a $\mathrm{CH}_{3} \mathrm{Hg}$ dose of $0.5 \mathrm{mg} / \mathrm{kg}$.

between methods is that toxicant concentrations are measured in the blood in the present study as opposed to whole-body measurements. These differences in methodology could account for the differences in bioavailability estimates and suggest that bioavailability estimates using these more conventional approaches may overestimate the true oral bioavailability of $\mathrm{CH}_{3} \mathrm{Hg}$ from food. Other differences between studies include the type of food, quantity of food, health of the fish (e.g., residual effects from surgery, $48 \mathrm{~h}$ fasting period prior to dosing), the species of fish, and water quality differences (e.g., temperature). One or a combination of these factors may have contributed to the lower estimates obtained for bioavailability using the current methodology relative to the more conventional methods.

There was large interanimal variation in the bioavailability estimates. However, most of the variation in bioavailability was clearly due to differences in the amount of food gavaged to the fish. There was a decrease in oral bioavailability with an increase in the amount of food gavaged (Fig. 2, top), which

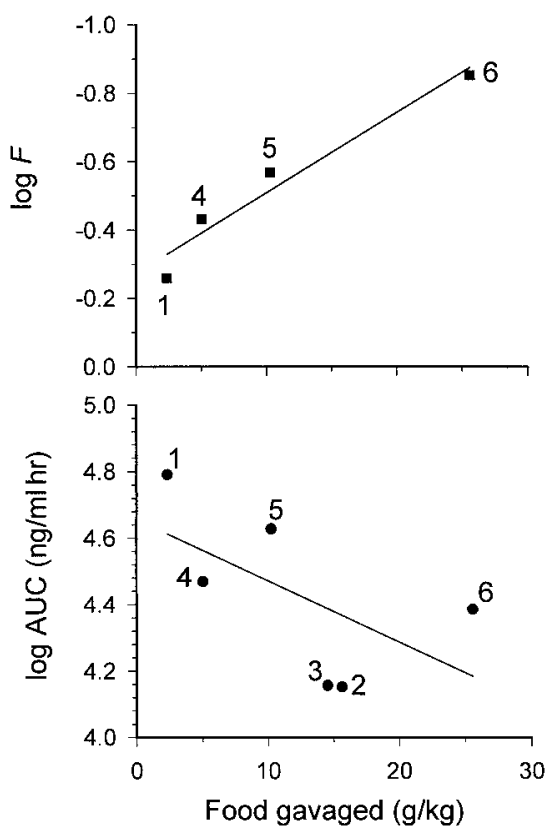

Fig. 2. Log of oral bioavailability (top) and oral area under the curve (AUC) (bottom) as a function of the amount of food gavaged ( $\mathrm{g}$ food/ $\mathrm{kg}$ fish). The numbers on the plots represent the number designated for the individual catfish was attributable to differences in the AUC after oral dosing (Fig. 2, bottom). These results suggest that the absorption efficiency of $\mathrm{CH}_{3} \mathrm{Hg}$ from the gut decreased as the quantity of food increased. A number of physiological factors may influence the extent of absorption including gastric emptying rate (if little absorption occurs from the stomach), intestinal transit time (which determines the time available for absorption to occur), and gastrointestinal (GI) blood flow. Increasing the amount of food gavaged to the fish could have increased gastric emptying rate and decreased intestinal transit time and thus decreased the absorption efficiency of $\mathrm{CH}_{3} \mathrm{Hg}$ from the gut. These results suggest that if smaller food volumes were used, bioavailability estimates from the present study may have been comparable to the higher bioavailability estimates obtained in previous studies [2,9-11]. The volume of food gavaged to a fish had a large affect on bioavailability estimates in the present study and needs to be included as a parameter when predicting the bioaccumulation of a toxicant from a food source.

There was a noticeable lag time observed after dosing before $\mathrm{CH}_{3} \mathrm{Hg}$ appeared in the blood. This lag time suggests that a dissociation from the food must occur before $\mathrm{CH}_{3} \mathrm{Hg}$ can be absorbed or limited absorption occurs in the stomach and that the food must pass into the intestine before absorption can occur. Limited absorption in the stomach would be supported by a previous study [26], which found that food orally gavaged to channel catfish at $21^{\circ} \mathrm{C}$ did not begin to reach the intestine in significant amounts until 4 to $6 \mathrm{~h}$. This agrees with the observed lag-time estimate of $3.4 \mathrm{~h}$, suggesting that the dose must be transferred from the stomach into the intestines before absorption of $\mathrm{CH}_{3} \mathrm{Hg}$ can occur. Additional support for these mechanisms comes from an oral bioavailability study using the organophosphorous insecticide chlorpyrifos in channel catfish [14]. Channel catfish were exposed to chloropyrifos under conditions similar to the present study and displayed a plasma concentration-time profile qualitatively similar to the $\mathrm{CH}_{3} \mathrm{Hg}$ blood profile [14]. The absorption rate of chlorpyrifos was thought to be partly influenced by dissolution from the gavaged pellets [14]. Both the dissociation of $\mathrm{CH}_{3} \mathrm{Hg}$ from the pelleted food and limited absorption in the stomach likely contributed to the lag time seen in the present study.

Toxicokinetic parameter estimates were similar whether noncompartmental or compartmental methods were used (Table 1). Parameter estimates from compartmental analysis after IA injection of $\mathrm{CH}_{3} \mathrm{Hg}$ in the present study were quantitatively similar to the estimates derived from a previous study with 
$\mathrm{CH}_{3} \mathrm{Hg}$ in channel catfish [17]. This would suggest that prior exposure to orally dosed $\mathrm{CH}_{3} \mathrm{Hg}$ has no obvious effect on the kinetics of a subsequent IA dose. Bioavailability estimates, on the other hand, were higher using AUC estimates from noncompartmental analyses then when using AUC estimates from compartmental analyses (Table 2). These differences in bioavailability were due to lower IA AUC estimates using noncompartmental methods compared to compartmental methods (Tables 1, 2). Even though different methods yielded slightly different toxicokinetic parameters (i.e., AUC) the overall conclusions remained unchanged.

While both noncompartmental and compartmental methods provided similar results, each method has its advantages and disadvantages. Because the noncompartmental approach is the easiest to apply, it is perhaps the most generally useful in bioavailability estimates of toxicants in fish. However, compartmental methods provide more information on the distribution and persistence of a compound in fish and are useful in simulating the accumulation of a xenobiotic under hypothetical exposures in the field. When possible, both methods should be used as they provide a more comprehensive estimate of the accumulation and persistence of toxicants in the animal.

In contrast to studies of therapeutic compounds used clinically and in aquaculture, bioavailability measurements using the present methodology are underutilized in ecotoxicology. This method for estimating bioavailability offers several advantages over conventional measurements of bioavailability because toxicant levels are measured in blood through time in the same animal therefore requiring fewer assumptions. This can be a more relevant parameter for certain ecotoxicological studies because blood concentrations can be more reflective of toxicant concentrations being delivered to target organs. These estimates may also be useful in ecological and human risk assessment when predicting the bioaccumulation of toxicants in fish from food, as it relates to consumption by humans or other species. In addition, blood concentrations following oral and IA dosing can be measured sequentially in the same fish, as opposed to two or more fish. This would reduce overall variation in the bioavailability estimate, because interanimal variation in the uptake and kinetics of toxicants would not be included in the estimate. Conventional bioavailability estimates typically measure the total amount of toxicant in the whole animal at a single time point, which, for lipophilic compounds, may be more indicative of storage tissue levels [27] than target organ concentrations. Although conventional methods will provide an adequate estimation of bioavailability provided the chemical has a slow elimination phase, they can underestimate bioavailability for chemicals that are rapidly eliminated or metabolized. Conventional methods can also overestimate bioavailability if unassimilated toxicant is present in the gut. Estimating bioavailability using the present methodology can minimize these problems. As ecological risk assessment requirements demand more predictive power and accuracy, methods are needed to measure more accurately the concentration reaching internal target organs. This demand will also require the generation of better parameters allowing development of pharmacokinetic models that have high predictive power beyond the dataset used to parameterize them. The methods described in the current study should foster the generation of such information.

Acknowledgement-This research was supported by Financial Assistance Award DE-FC09-96SR18546 from the U.S. Department of Energy to the University of Georgia Research Foundation.

\section{REFERENCES}

1. Bloom N. 1992. On the chemical form of mercury in edible fish and marine invertebrate tissue. Can J Fish Aquat Sci 49:1010-1017.

2. Phillips GR, Buhler DR. 1978. The relative contributions of methylmercury from food or water in rainbow trout (Salmo gairdneri) in a controlled laboratory environment. Trans Am Fish Soc 107:853861.

3. Rand GM. 1995. Fundamentals of Aquatic Toxicology. Taylor \& Francis, Washington, DC, USA.

4. Gibaldi M. 1991. Biopharmaceutics and Clinical Pharmacokinetics. Lea \& Febiger, Philadelphia, PA, USA.

5. Horsberg TE, Hoff KA, Nordmo R. 1996. Pharmacokinetics of florfenicol and its metabolite florfenicol amine in Atlantic salmon. $J$ Aquat Anim Health 8:292-301.

6. Martinsen B, Horsberg TE, Varma KJ, Sams R. 1993. Single dose pharmacokinetic study of florfenicol in Atlantic salmon (Salmo solar) in sea water at $11^{\circ} \mathrm{C}$. Aquaculture 112:1-11.

7. Martinsen B, Sohlberg S, Horsberg TE, Burke M. 1993. Single dose kinetic study of sarafloxacin after intravascular and oral administration to cannulated Atlantic salmon (Salmo solar) held in sea water at $12^{\circ} \mathrm{C}$. Aquaculture 118:49-52.

8. Newman MC. 1995. Quantitative Methods in Aquatic Ecotoxicology. CRC/Lewis, Boca Raton, FL, USA, p 426.

9. Sharpe MS, DeFreitas ASW, McKinnon AE. 1977. The effect of body size on methylmercury clearance by goldfish (Carassius auratus). Environ Biol Fishes 2:177-183.

10. Giblin FJ, Massaro EJ. 1973. Pharmacodynamics of methyl mercury in the rainbow trout (Salmo gairdneri): Tissue uptake, distribution and excretion. Toxicol Appl Pharmacol 24:81-91.

11. Lock RAC. 1975. Uptake of methylmercury by aquatic organisms from water and food. In Koeman JH, Strik JJTWA, eds, Sublethal Effects of Toxic Chemicals on Aquatic Animals, Elsevier, Amsterdam, The Netherlands, pp 61-79.

12. Jernelov A. 1968. Laboratory experiments on the change of mercury compounds from one into another. Vatten 24:360-362.

13. Phillips GR, Gregory RW. 1979. Assimilation efficiency of dietary methylmercury by northern pike (Esox lucius). J Fish Res Board Can 36:1516-1519.

14. Barron MG, Plakas SM, Wilga PC. 1991. Chlorpyrifos pharmacokinetics and metabolism following intravenous and dietary administration in channel catfish. Toxicol Appl Pharmacol 108:474-482.

15. U.S. Environmental Protection Agency. 1978. Environmental monitoring series. Quality Assurance Guidelines for Biological Testing. EPA-600/4-78-043. Cincinnati, OH.

16. Schultz IR, Hayton WL. 1993. The toxicokinetics of trifluralin in rainbow trout. Aquat Toxicol 26:287-306.

17. Schultz IR, Newman MC. 1997. Methyl mercury toxicokinetics in channel catfish (Ictalurus punctatus) and largemouth bass (Micropterus salmoides) after intravascular administration. Environ Toxicol Chem 16:990-996.

18. Jolly DW, Mawdesley-Thomas LE, Bucke D. 1972. Anesthesia of fish. Vet Rec 91:424-426.

19. Filippelli M. 1987. Determination of trace amounts of organic and inorganic mercury in biological materials by graphite furnace atomic absorption spectrometry and organic mercury speciation by gas chromatography. Anal Chem 59:116-119.

20. McKim JM, Nichols JW, Lien GJ, Bertelsen SL. 1994. Respiratorycardiovascular physiology and chloroethane gill flux in the channel catfish Ictalurus punctatus. J Fish Biol 44:527-547.

21. DiStefano JJ. 1982. Noncompartmental vs. compartmental analysis: Some basis for choice. Am J Physiol 243:R1-R6.

22. Wagner JG. 1988. Pharmacokinetics: Past developments, present issues, future challenges. In Welling PG, Tse LS, eds, Pharmacokinetics: Regulatory, Industrial, Academic Perspectives, Dekker, New York, NY, USA.

23. Yamaoka K, Nakagawa T, Uno T. 1978. Statistical moments in pharmacokinetics. J Pharmacokinet Biopharm 6:547-558.

24. Gibaldi M, Perrier D. 1982. Pharmacokinetics. Dekker, NY, USA.

25. Gabrielsson J, Weiner D. 1994. Pharmacokinetic and Pharmacodynamic Data Analysis: Concepts and Applications. Swedish Pharmaceutical Press, Stockholm, Sweden.

26. Shrable JB, Tiemeier OW, Deyoe CW. 1969. Effects of temperature on rate of digestion by channel catfish. Prog Fish Cult 31:131-138.

27. Lassiter RR, Hallam TG. 1990. Survival of the fattest: Implications for acute effects of lipopholic chemicals on aquatic populations. Environ Toxicol Chem 9:585-595. 